\title{
Identification of deep trap levels from thermally stimulated current spectra of semi-insulating CdZnTe detector material
}

\author{
M. Pavlović, ${ }^{\text {a) }}$ M. Jakšić, H. Zorc, and Z. Medunić \\ Ruđer Bošković Institute, Bijenička c. 54, P. O. Box 180, 10002 Zagreb, Croatia
}

(Received 1 December 2007; accepted 22 May 2008; published online 24 July 2008)

\begin{abstract}
Deep trap levels in the semi-insulating (SI) CdZnTe detector material were characterized by simultaneous multiple peak analysis based on thermally stimulated current (TSC) measurements. In our TSCs that have been published previously electron hole pairs were created through the use of proton beam irradiation. Charge carriers were captured in deep traps and afterward released by thermal emission, which was recorded in the 90-300 K range. We showed that the obtained TSC spectra could be well fitted with a unique set of 14 different deep traps, which were all simultaneously and completely characterized. The obtained trap data are in good accordance with earlier deep trap characterizations of the other authors obtained on similar SI CdZnTe materials using different methods. (C) 2008 American Institute of Physics. [DOI: 10.1063/1.2959354]
\end{abstract}

\section{INTRODUCTION}

Deep traps in semi-insulating (SI) materials can be characterized by several techniques. Among them, the thermally stimulated current ${ }^{1-3}$ (TSC) and the thermoelectric emission spectroscopy $^{4-6}$ (TEES) are routinely employed on SI III-V semiconductors (e.g., GaAs, InP, and GaN) as well as on SI CdZnTe detector materials. ${ }^{7-9}$ In this work, we characterize defects with deep levels (traps) in the band gap of SI CdZnTe $\left(E_{g}=1.57 \mathrm{eV}\right.$ at $\left.300 \mathrm{~K}\right)$ ternary detector material. Because the device performance is greatly dependent on these defects, proper characterization is very important. Trap filling is a characterization method that is commonly performed by photogeneration of charge carriers via illumination with the over-band-gap light energies at low temperatures. However, the amplitude of the signals obtained from the TSC measurements is easier to measure than the amplitude of the signals obtained from TEES measurements; TEES has an advantage in that it can distinguish between electrons and hole traps.

Recently, many papers have been published on the use of focused ion beams in the characterization of semiconductors and devices. The theory of the ion beam induced charge (IBIC) was summarized by Vittone et al., ${ }^{10}$ whose work, especially in understanding the process of signal evolution, initiated the use of scanning ion microbeams. Charge collection efficiency (CCE) maps obtained by scanning a microbeam over the sample surface give qualitative descriptions of the sample as well as the other valuable data such as the carrier's mobility lifetime $(\mu \tau)$ product, diffusion length, and the width of the depletion zone in semiconductor devices. Timeresolved IBIC (TRIBIC) is a technique through which the electric response of material to a single incident ion can be directly monitored with respect to time. For the pulse recording and numerical fitting of transients, TRIBIC was applied using the procedure introduced by Manfredotti et al. ${ }^{11} \mathrm{SI}$ CdZnTe material was examined with both the IBIC and TRIBIC techniques at different temperatures. ${ }^{12}$ The obvious

\footnotetext{
${ }^{a)}$ Author to whom correspondence should be addressed. Electronic mail: pavlovic@irb.hr.
}

change in CCE maps as well as of the TRIBIC transients with temperature was recorded and explained by the presence of trap levels in the material. ${ }^{12}$

Medunić et al. ${ }^{13}$ showed that the use of ion microbeams at different temperatures could be useful for studying semiconductors by applying IBIC (TRIBIC) in conjunction with TSC, which is an improvement over the TSC method alone. Besides rough-and-ready characterization and enumeration of trap levels in the CdZnTe material, the TSC method distinguishes between electron and hole levels. ${ }^{13}$

In this work, we made further steps in the characterization of deep traps. We used the above described TSC spectra, ${ }^{13}$ in which charge carriers had been created by a proton microbeam. To these TSC data we applied simultaneous multiple peak analysis ${ }^{14,15}$ (SIMPA) in order to achieve simultaneous and full characterization of all deep traps found in the examined SI CdZnTe. Basic principles of the SIMPA characterization method are presented in Sec. III.

The results of the procedure revealed the existence of 14 different deep traps in the examined samples. Their full and precise characterization, enumeration, and cataloging were performed. These findings proved an earlier assumption that the measured TSC spectra are composed of many overlapping peaks. This is especially true in the region of the dominant peak at $168 \mathrm{~K}$; in previous studies, when this was treated as an individual peak, its characterization gave an unphysically small capture cross section $\left(\sim 10^{-25} \mathrm{~cm}^{2}\right){ }^{13}$

Our trap data are in a good accordance with earlier deep trap characterization results, obtained by other authors on similar materials using TSC, TEES, and other characterization methods. These findings show that the use of a proton beam for the creation of charge carriers leads to valuable TSC measurements and consequently to reliable and complete deep trap characterization.

\section{EXPERIMENTAL}

In order to create electron-hole pairs, a beam of $5 \mathrm{MeV}$ protons focused on a spot of several micrometers was scanned in a nuclear microprobe chamber over the lateral 
surface (between the electrical contacts) of CdZnTe sample. ${ }^{13}$ The total beam fluence was $2 \times 10^{7}$ protons, which is below the value where the material damage can become important. The penetration depth of the proton beam in CdZnTe (assumed density $5.8 \mathrm{~g} / \mathrm{cm}^{3}$ ) was $150 \mu \mathrm{m}$ as determined using the TRIM code. ${ }^{16}$ Such penetration depths assure that the surface effects are negligible. Charge carriers were created and captured by deep traps at low temperature and then released by thermal emission, which was recorded as a function of temperature in a $90-300 \mathrm{~K}$ range (TSC spectrum). The heating rate was $0.1-0.5 \mathrm{~K} / \mathrm{s}$. Bias voltage was applied at all times during the irradiation process. Current through the sample was measured by heating at room temperature by the use of Keithley 6514 electrometer. Bias voltage of $200 \mathrm{~V}$ was not exceeded in order not to cross the 250 $\mathrm{V}$ limit of the Keithley instrument.

The samples in this study had a measured resistivity of $\rho>10^{10} \Omega \mathrm{cm}$. CdZnTe grade detectors were provided by $\mathrm{eV}$ Products. They have a cubic shape with dimensions 5 $\times 5 \times 5 \mathrm{~mm}^{3}$ and were furnished with sputtered or electroless $\mathrm{Au}$ contacts placed on two opposite cube faces. The samples were mounted between two spring loaded Au contacts ensuring good electric contacts during the measurements. Thermal contact was achieved through the bottom side of the sample, which was placed on the copper body of the sample holder. During the experiments, the samples were kept in the dark to prevent any excitation of charge carriers by light, thus avoiding unintentional deep trap filling. Samples were irradiated homogeneously over one lateral side of the sample (between the contacts) or over some specific areas of that sample side. This could, in principle, enable studies of inhomogeneities in spatial distribution of traps. Additional experimental details can be found elsewhere. ${ }^{12,13}$

\section{SIMPA CHARACTERIZATION METHOD}

The SIMPA method is an analytical procedure for simultaneous and complete characterization of all deep traps found in the examined semiconductor material. Previously, it has been used to characterize deep traps/levels in SI GaAs (Refs. 14 and 15) and SI GaN. ${ }^{17,18}$

This method is based on the assumption that the TSC spectrum is a sum of TSC peaks belonging to the specific deep levels and the dark current $I_{\text {dark }}(T)=C \exp \left[-E_{\mathrm{DD}} / k T\right]$, where $C$ is a constant and $E_{\mathrm{DD}}$ is a deep donor level analogous to the "EL2" midgap level in SI GaAs. ${ }^{19}$ The $E_{\mathrm{DD}}$ level plays important role in electrical compensation and the strength of the dark current. Because the resistivity of our samples was on the order of $10^{10} \Omega \mathrm{cm}$, one can infer that electrical compensation was achieved.

Temperature dependent fitting function $I_{\mathrm{SIMPA}}(T)$ including the sum of all features of the TSC spectrum is given by ${ }^{14}$

$$
I_{\mathrm{SIMPA}}(T)=\sum_{i=1}^{m} \boldsymbol{I}_{\mathrm{TSC}}^{i}(T)+\boldsymbol{I}_{\mathrm{dark}}(T),
$$

where $I_{\mathrm{TSC}}^{i}(T)$ represents the $i$ th individual TSC peak and $m$ is the total number of different deep traps calculated. The measured TSC spectra were fitted using the theoretical TSC function, yielding deep trap parameters as output.
In the "first order kinetics" approximation, a single TSC peak resulting from an electron trap can be described as ${ }^{14}$

$$
\begin{aligned}
\boldsymbol{I}_{\mathrm{TCS}}^{i}(T)= & K_{G} \mu N_{i} \tau D_{t} T^{2} \exp \left[-\frac{E_{a, i}}{k T}-\frac{k D_{t}}{\beta E_{a, i}} T^{4} e^{-E_{a, i} / k T}\right. \\
& \left.\times\left(1-4 \frac{k T}{E_{a, i}}+20 \frac{k^{2} T^{2}}{E_{a, i}^{2}}\right)\right],
\end{aligned}
$$

where $K_{G}$ denotes a geometrical factor and $N_{i}$ is the carrier density of the filled $i$ th deep trap at the beginning of the temperature ramp. The variable $E_{a, i}$ is the activation energy of the $i$ th trap, and $\beta$ is the heating rate; $D_{t, i}$ is the temperature independent, trap dependent coefficient that includes the electron (or hole) capture cross section $\left(\sigma_{i}\right)$ measured in $\mathrm{cm}^{2}$ and is defined as ${ }^{14} D_{t, i}=3 \times 10^{21}\left(\mathrm{~m}^{*} / \mathrm{m}_{0}\right) \sigma_{i}$, where $m_{0}$ and $\mathrm{m}^{*}$ represent the electron (or hole) rest and effective masses, respectively. ${ }^{20}$ According to data from Ref. 21, for the same SI CdZnTe sample as we used in this experiment (eV Products), the $\left(\mathrm{m}^{*} / \mathrm{m}_{0}\right)$ ratio is taken to be 0.112 . The function defined by Eq. (1) was used as the fitting function with $E_{a, i}$, $\sigma_{i}$, and $N_{i}$ taken as unknowns. $K_{G}$ and $\beta$, defined above, are constants whose values were determined experimentally. Analysis shows, however, that these parameters have a measurable dependence on peak characteristics. $N_{i}, E_{a, i}$, and $\sigma_{i}$ primarily determine peak height, position, and width, respectively. Due to the relative interdependence of these parameters, a change of $\sigma_{i}$ up to $20 \%$ from the best fit value can be compensated by a change of $E_{a}($ for $\approx 1 \%)$ and $N_{i}($ for $\approx 5 \%$ ) with good resulting fits. Hence, the uniqueness of the fit is ensured within the confidence limits of $\pm 20 \%, \pm 1 \%$, and $\pm 5 \%$, for $\sigma_{i}, E_{a}$, and $N_{i}$, respectively. ${ }^{14,15}$

In this case, the $\mu \tau$ product at $300 \mathrm{~K}$ was taken to be $1.6 \times 10^{-4} \mathrm{~cm}^{2} / \mathrm{V}$, corresponding to the value estimated from previous measurements on the same type of material ${ }^{21}$ as ours (eV Products). For lower temperatures, $\mu \tau$ was calculated based on the approximation that $\tau$ is nearly constant (in whole specified temperature-range), and $\mu$ exponentially falls off with temperature ${ }^{21}$ from $3000 \mathrm{~cm}^{2} / \mathrm{V} \mathrm{s}$ at $100 \mathrm{~K}$ to $950 \mathrm{~cm}^{2} / \mathrm{V}$ s at $300 \mathrm{~K}$.

Generally, none of the 14 deep levels used in SIMPA simulations was constructed artificially or assumed without experimental support, i.e., without being well resolved or displaying an even dominant peak in at least one of the measured TSC spectra and/or from the characterization results for deep traps on similar SI CdZnTe materials found in the literature. All these results were obtained by means of TSC, TEES, and/or with the other characterization methods, such as photoluminiscence (PL), ${ }^{21}$ cathodoluminescence (CL), ${ }^{22,23}$ deep level transient spectroscopy (DLTS), ${ }^{23,24}$ deep level optical spectroscopy (DLOS) ${ }^{24}$ photoinduced current transient spectroscopy (PICTS), ${ }^{7,92,23,25-27}$ or photoconductivity. ${ }^{28}$

\section{RESULTS AND DISCUSSION}

Figure 1 presents the SIMPA fit of a smooth TSC curve obtained in our earlier work. ${ }^{13}$ The thick solid curve represents the fitted (theoretical) $I_{\text {SIMPA }}$ function defined by Eq. (1). The dotted curve is the measured TSC spectrum where $\beta=0.1 \mathrm{~K} / \mathrm{s}$ with a bias voltage $V=-200 \mathrm{~V}$. The solid thin 


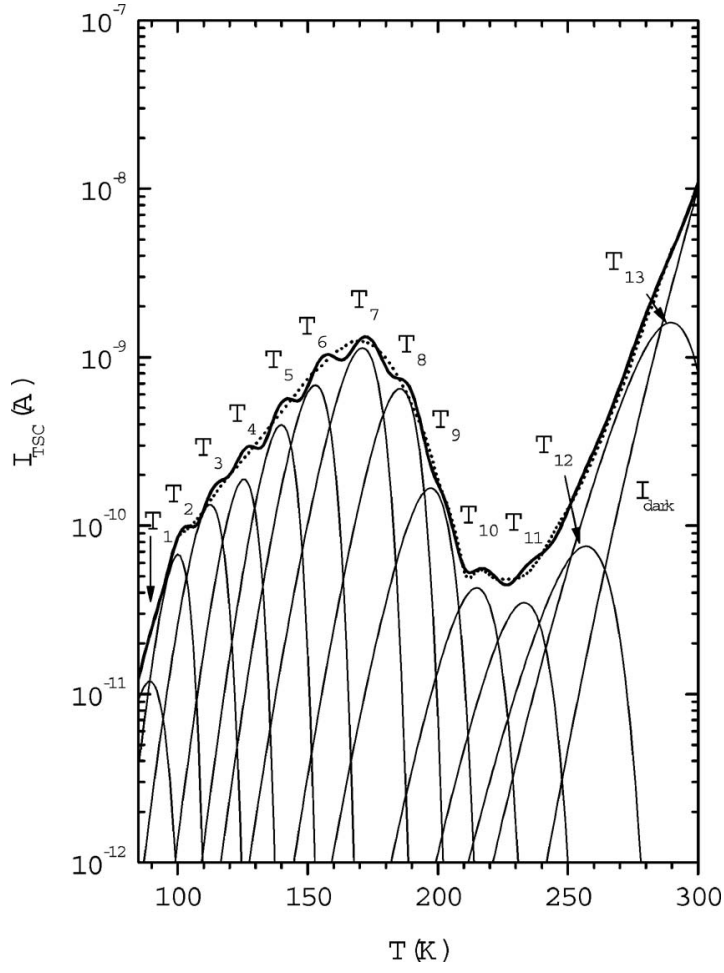

FIG. 1. The SIMPA fit of TSC curve obtained in Ref. 13. The thick solid curve depicts the fitted (theoretical) $I_{\text {SIMPA }}$ function defined by Eq. (1). The dotted curve represents the measured TSC spectrum $(\beta=0.1 \mathrm{~K} / \mathrm{s}$ and a bias voltage $V=-200 \mathrm{~V})$. The thin solid curves represent the individual TSC peaks [defined by Eq. (2)].

curves correspond to each individual TSC peak belonging to a respective deep trap (level). Earlier approaches to TSC spectrum analysis took into account a single peak with a maximum at $168 \mathrm{~K}$, which led to a physically unrealistic value of the capture cross section. ${ }^{13}$ It was apparent that the whole TSC spectrum should be treated as the composition of many overlapping individual TSC peaks. As seen in Fig. 1, a very good fit was achieved using a theoretical function composed of 13 different deep traps plus the dark current mediated by the deep donor level $E_{\mathrm{DD}}$.

Figure 2 shows the SIMPA fit of the TSC spectrum of the CdZnTe sample, this time irradiated in a smaller area and biased at $V=-200 \mathrm{~V}$. This time, the sample was heated at $\beta=0.5 \mathrm{~K} / \mathrm{s}$. In this case, a fewer electron-hole pairs were generated resulting in a lower trap-filling rate. In comparison to the single broad TSC peak seen in Fig. 1, a more pronounced structure of TSC peaks can be observed in Fig. 2. This confirms the assumption ${ }^{13}$ that the peak in the measured TSC spectrum is composed of several overlapping peaks. The structure appeared because of the higher heating rate used in this experiment. This higher heating rate also caused a shift in the TSC peak maxima by approximately $10 \mathrm{~K}$ to a higher temperature value in comparison to the values from Fig. 1. This spectrum was also very well fitted by the theoretical curve composed of the same set of 14 deep levels (including $E_{\mathrm{DD}}$ ), as in the first case (see Fig. 1).

We found that among fitting variables, $\sigma_{i}$ is the most sensitive parameter. ${ }^{14,15,20}$ It has the strongest impact on a single peak breadth. ${ }^{20}$ Neighboring peaks influence each other, especially in overlapping areas and errors accumulate.

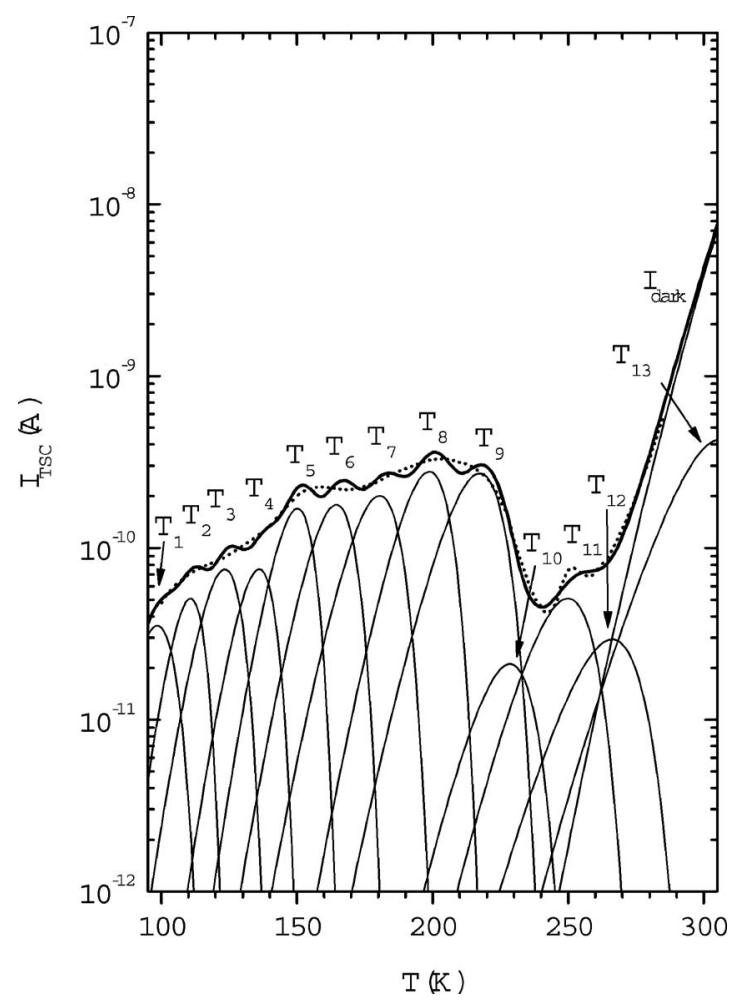

FIG. 2. The SIMPA fit of the TSC curve obtained in Ref. 13. The thick solid curve represents the fitted (theoretical) $I_{\text {SIMPA }}$ function defined by Eq. (1). The dotted curve depicts the measured TSC spectrum $(\beta=0.5 \mathrm{~K} / \mathrm{s}$ and a bias voltage $V=-200 \mathrm{~V})$. The thin solid curves represent the individual TSC peaks [defined by Eq. (2)].

This is probably the main reason why our fitted curves are not perfectly superimposed to the experiment.

Results determined from the best fits are presented in Table I. The first column presents the assignment of each of the TSC peaks, the second shows the value of the trap activation energy in $\mathrm{eV}$, the third presents the capture cross sections in $\mathrm{cm}^{2}$, and the fourth gives the position of each peak maximum in $K$. Columns 2-4 refer to the TSC measurements with $\beta=0.1 \mathrm{~K} / \mathrm{s}$ and columns $5-7$ refer to the same parameters for measurements with $\beta=0.5 \mathrm{~K} / \mathrm{s}$. The results obtained for $\sigma$ are in accordance with the literature, where most of the traps have a capture cross section in the $10^{-18}-10^{-12} \mathrm{~cm}^{2}$ range.

Table II presents deep trap concentrations calculated using Eq. (3), where column 2 refers to the data plotted in Fig. 1 and column 3 to the case shown in Fig. 2. Most of the trap concentrations were found to be in the $10^{11}-10^{13} \mathrm{~cm}^{-3}$ range. The highest concentration was obtained for the $T_{12}$ trap $\left(\sim 10^{14} \mathrm{~cm}^{-3}\right)$. These results are three to five orders of magnitude lower than those obtained in most previous studies, ${ }^{21,26,28}$ in which the total concentrations of ionized residual impurities (both donors and acceptors) and native defects are estimated to be in the order of $10^{16} \mathrm{~cm}^{-3}$. This result can be explained by noting that the conditions in our case are probably insufficient for complete trap filling, although in the literature defect concentrations sometimes can indeed be much smaller ${ }^{29}$ (four to five orders of magnitude) than generally expected.

A critical comparison of levels/traps obtained in this 
TABLE I. Deep trap parameters obtained by the SIMPA method from the best fits of measured TSC spectra. Columns $2-4$ refer to the measurement with $\beta=0.1 \mathrm{~K} / \mathrm{s}$ and columns $5-7$ refer to the measurement with $\beta=0.5 \mathrm{~K} / \mathrm{s}$.

\begin{tabular}{|c|c|c|c|c|c|c|}
\hline Deep trap & $\begin{array}{c}E_{a} / \mathrm{eV} \\
\text { Activ. energy }\end{array}$ & $\begin{array}{c}\sigma / \mathrm{cm}^{2} \\
\text { Capture cross sect. }\end{array}$ & $\begin{array}{c}T_{m} / \mathrm{K} \\
\text { Peak max at } 0.1 \mathrm{~K} / \mathrm{s}\end{array}$ & $\begin{array}{c}E_{a} / \mathrm{eV} \\
\text { Capture cross sect. }\end{array}$ & $\begin{array}{c}\sigma / \mathrm{cm}^{2} \\
\text { Capture cross sect. }\end{array}$ & $\begin{array}{c}T_{m} / \mathrm{K} \\
\text { Peak max } \\
\text { at } 0.5 \mathrm{~K} / \mathrm{s}\end{array}$ \\
\hline$T_{1}$ & 0.101 & $3.0 \times 10^{-21}$ & 90 & 0.100 & $3.0 \times 10^{-21}$ & 98 \\
\hline$T_{2}$ & 0.170 & $1.8 \times 10^{-18}$ & 104 & 0.174 & $1.8 \times 10^{-18}$ & 110 \\
\hline$T_{3}$ & 0.177 & $3.0 \times 10^{-19}$ & 113 & 0.179 & $3.0 \times 10^{-19}$ & 127 \\
\hline$T_{4}$ & 0.230 & $6.0 \times 10^{-18}$ & 124 & 0.234 & $6.0 \times 10^{-18}$ & 138 \\
\hline$T_{5}$ & 0.276 & $2.4 \times 10^{-17}$ & 140 & 0.279 & $2.4 \times 10^{-17}$ & 151 \\
\hline$T_{6}$ & 0.298 & $9.1 \times 10^{-18}$ & 155 & 0.291 & $6.1 \times 10^{-18}$ & 165 \\
\hline$T_{7}$ & 0.319 & $3.5 \times 10^{-18}$ & 173 & 0.315 & $3.5 \times 10^{-18}$ & 183 \\
\hline$T_{8}$ & 0.392 & $0.6 \times 10^{-16}$ & 188 & 0.397 & $0.6 \times 10^{-16}$ & 200 \\
\hline$T_{9}$ & 0.400 & $1.6 \times 10^{-17}$ & 198 & 0.409 & $1.1 \times 10^{-17}$ & 221 \\
\hline$T_{10}$ & 0.446 & $2.3 \times 10^{-17}$ & 215 & 0.446 & $2.1 \times 10^{-17}$ & 233 \\
\hline$T_{11}$ & 0.490 & $3.5 \times 10^{-18}$ & 233 & 0.492 & $3.8 \times 10^{-18}$ & 253 \\
\hline$T_{12}$ & 0.505 & $2.4 \times 10^{-17}$ & 256 & 0.499 & $2.3 \times 10^{-17}$ & 270 \\
\hline$T_{13}$ & 0.628 & $2.8 \times 10^{-17}$ & 291 & 0.627 & $2.8 \times 10^{-17}$ & 308 \\
\hline$E_{D D}$ & 0.99 & $\ldots$ & & 0.99 & - & \\
\hline
\end{tabular}

work with levels obtained by other authors achieved using the same or very similar material types follows. There is good agreement between our results and those reported in the literature regarding the activation energies, but there is less agreement in the capture cross sections. There is a wide range of results reported in the literature (over five or more orders of magnitude) for the very same trap because of the exponential dependence on temperature. In the literature, one can rarely find complete parameter data for specific individual deep traps. Some authors give $E_{a}$ with or without $\sigma$; some just report raw TSC [or TEES and PICTS (Ref. 25)] with only characteristic peaks assigned. Trap concentrations also are presented very rarely. The authors usually apply different heat rates in their measurements. This results in misidentification of the same levels or identification of previously occurring levels as a "new" level. These facts mean that previous works complicated the deep trap analysis and cataloging, probably giving an unrealistically large number of more than 30 different levels ${ }^{26}$ reported in SI CdZnTe and similar materials (undoped and/or doped). The analysis of our results follows below.

TABLE II. Deep trap concentrations obtained from the best SIMPA fits of the measured TSCs (Ref. 13) for $\beta=0.1 \mathrm{~K} / \mathrm{s}\left(N_{i}^{*}\right)$ and $\beta=0.5 \mathrm{~K} / \mathrm{s}\left(N_{i}^{* * *}\right)$.

\begin{tabular}{ccc}
\hline \hline Deep traps & $N_{i}^{*}\left(\mathrm{~cm}^{-3}\right)$ & $N_{i}^{* *}\left(\mathrm{~cm}^{-3}\right)$ \\
\hline$T_{1}$ & $1.7 \times 10^{11}$ & $2.6 \times 10^{10}$ \\
$T_{2}$ & $1.0 \times 10^{12}$ & $0.9 \times 10^{11}$ \\
$T_{3}$ & $1.1 \times 10^{12}$ & $1.6 \times 10^{11}$ \\
$T_{4}$ & $2.1 \times 10^{12}$ & $1.6 \times 10^{11}$ \\
$T_{5}$ & $4.3 \times 10^{12}$ & $4.2 \times 10^{11}$ \\
$T_{6}$ & $1.7 \times 10^{13}$ & $0.7 \times 10^{12}$ \\
$T_{7}$ & $1.1 \times 10^{13}$ & $0.6 \times 10^{12}$ \\
$T_{8}$ & $1.2 \times 10^{13}$ & $1.1 \times 10^{12}$ \\
$T_{9}$ & $3.5 \times 10^{12}$ & $1.4 \times 10^{12}$ \\
$T_{10}$ & $1.1 \times 10^{12}$ & $2.1 \times 10^{11}$ \\
$T_{11}$ & $2.5 \times 10^{12}$ & $2.0 \times 10^{11}$ \\
$T_{12}$ & $0.7 \times 10^{14}$ & $0.8 \times 10^{13}$ \\
$T_{13}$ & $1.4 \times 10^{12}$ & $0.8 \times 10^{12}$ \\
\hline
\end{tabular}

Trap $T_{1}$ with an activation energy of $0.1 \mathrm{eV}$ and a capture cross section of $3 \times 10^{-21} \mathrm{~cm}^{2}$ may correspond to the shallow levels (or band) of the so called $A$ centers ${ }^{8,25,29,30}$ usually reported in the range of $0.12-0.15 \mathrm{eV}$, in particular, ${ }^{23}$ $A_{0}\left(0.12 \mathrm{eV}, 2 \times 10^{-16} \mathrm{~cm}^{2}\right), A\left(0.14 \mathrm{eV}, 1.0 \times 10^{16} \mathrm{~cm}^{2}\right)$, and $A_{1}\left(0.15 \mathrm{eV}, 4 \times 10^{-17} \mathrm{~cm}^{2}\right)$. The microscopic origin of this level has been attributed to $\left(V_{\mathrm{Cd}^{-}}-\mathrm{In}_{\mathrm{Cd}}\right),\left(V_{\mathrm{Cd}^{-}} \mathrm{Cl}_{\mathrm{Te}}\right)$, or $\left(V_{\mathrm{Cd}}-\mathrm{In}_{\mathrm{Te}}\right)$ complexes. ${ }^{23,29}$ Traps with similar activation energies are also often identified as unavoidable impurities, forming donor ( $\mathrm{Al}, \mathrm{Ga}$, In, $\mathrm{F}, \mathrm{Cl}$, and $\mathrm{Br}$ ), and/or acceptor levels $(\mathrm{Li}, \mathrm{Na}, \mathrm{N}, \mathrm{O}, \mathrm{As}, \mathrm{Ag}$, and $\mathrm{Cu})$.

Traps $T_{2}$ and $T_{3}$ with $E_{a}$ of $0.170 \mathrm{eV}$ and $0.177 \mathrm{eV}$ and $\sigma$ of $1.8 \times 10^{-19} \mathrm{~cm}^{2}$ and $3.0 \times 10^{-18} \mathrm{~cm}^{2}$, respectively, correspond to level $A$ in Ref. $27\left(0.18 \mathrm{eV}, 4.96 \times 10^{-15} \mathrm{~cm}^{2}\right)$, level $B\left(0.20 \mathrm{eV}, 3.0 \times 10^{-16} \mathrm{~cm}^{2}\right)$ in Ref. 23, the TEES electron trap $E_{1}(0.2 \mathrm{eV})$ in Ref. 7, and level $A(0.16 \mathrm{eV}, 3.0$ $\times 10^{-16} \mathrm{~cm}^{2}$ ) from the work of Castaldini et al., ${ }^{22}$ where the origin was attributed to a common $A$ center or a $\mathrm{Cu}(\mathrm{Ag})$ impurity. Two other levels, one at $E_{C^{-}}-0.19 \mathrm{eV}$ and the other at $E_{V}+0.2 \mathrm{eV}$ (where $E_{V}$ denotes the valence band), similar to ours can be found in the DLTS results of Zerrai et al. ${ }^{24}$ The levels of these traps are also close to the $0.2 \mathrm{eV}$ hole trap level from the work of Lee et al., ${ }^{8}$ which was attributed to the $\mathrm{Cd}$ vacancy $V_{\mathrm{Cd}}$, which is a native defect. Finally, yet importantly, is the so called "oxygen" TEES level in CdTe in work of Awadalla et al. ${ }^{31}$ This level is in closest agreement to our results in both parameters $[0.184 \pm 0.011 \mathrm{eV},(7 \pm 4)$ $\left.\times 10^{-17} \mathrm{~cm}^{2}\right]$. The authors attributed it to the $\left(O_{\mathrm{Te}}-V_{\mathrm{Cd}}\right)^{-/ 2-}$ complex.

Trap $T_{4}\left(0.23 \mathrm{eV}, 6.0 \times 10^{-18} \mathrm{~cm}^{2}\right)$ corresponds nicely to the acceptor level $H_{1}$, which is a hole trap located at $0.23 \mathrm{eV}$ above the valence band, as found in TEES measurements of Zerrai et $a .^{7}$ It is also very close to level $B(0.25 \mathrm{eV}, 2.5$ $\times 10^{-16} \mathrm{~cm}^{2}$ ) of Castaldini et al..$^{22}$ obtained from their PICTS measurements and designated as a Zn-related level.

Trap $T_{5}\left(0.276 \mathrm{eV}, 2.4 \times 10^{-17} \mathrm{~cm}^{2}\right)$, according to $E_{a}$, corresponds to the $0.27 \mathrm{eV}$ level of Suzuki et $a .^{32}$ and of 
Larsen et al. ${ }^{33}$ It is also close to level $E_{2}(0.26 \mathrm{eV})$ observed in the TEES spectra obtained by Zerrai et al. $^{7}$

Trap $T_{6}\left(0.298 \mathrm{eV}, 9.1 \times 10^{-18} \mathrm{~cm}^{2}\right)$ with a peak at 155 $\mathrm{K}$ is at the same position as the peak of level $X$ found by Cavallini et al. ${ }^{25}$ The concentration of this level increased after low-energy neutron irradiation of their CdZnTe detectors and decreased after one year rest period.

Trap $T_{7}\left(0.319 \mathrm{eV}, 3.5 \times 10^{-18} \mathrm{~cm}^{2}\right)$ by activation energy corresponds very well with level $B(0.32 \mathrm{eV}, 2.43$ $\left.\times 10^{-15} \mathrm{~cm}^{2}\right)$ of Drighil et al. ${ }^{27}$ and with level $D(0.32 \mathrm{eV}$, $8 \times 10^{-16} \mathrm{~cm}^{2}$ ) of Castaldini et al., ${ }^{23}$ which is closer to the cross-section value in our traps. The defect in Ref. 27 was attributed to the impurity levels of $\mathrm{Cu}, \mathrm{Au}$, or $\mathrm{C}$, while in Ref. 23 the authors associated this level with the $\mathrm{Te}_{\mathrm{Cd}}$ (antisite) complex. In the work of Szeles, ${ }^{29}$ this antisite was connected with the level positioned at $0.34 \mathrm{eV}$ below the conduction band $E_{C}$.

Traps $T_{8}\left(0.392 \mathrm{eV}, 6.0 \times 10^{-17} \mathrm{~cm}^{2}\right)$ and $T_{9}(0.400 \mathrm{eV}$, $1.6 \times 10^{-17} \mathrm{~cm}^{2}$ ) are similar to the $0.4 \mathrm{eV}$ electron trap from Ref. 8, as attributed to a $\mathrm{Te}_{\mathrm{Cd}}$ related defect. This level could also be connected with level $E\left(0.43 \mathrm{eV}, 1 \times 10^{-14} \mathrm{~cm}^{2}\right)$ of Castaldini et al., ${ }^{23}$ which was attributed to $V_{\mathrm{Cd}}$. Level $Z$ in Ref. 25 is peaked at a similar position to our $T_{8}$ and/or $T_{9}$.

Trap $T_{10}\left(0.446 \mathrm{eV}, 2.3 \times 10^{-17} \mathrm{~cm}^{2}\right)$ in our TSC spectra is positioned at the same peak position as the PICTS level $J$ in Ref. 25 (215-233 K). At this position in the PICTS spectrum of Ref. 26, between strong peaks $P 3$ and $P 5$ there is a clearly visible shoulder indicating the presence of a trap in that position. A similar level called P5 (0.44 eV, 1 $\times 10^{-10} \mathrm{~cm}^{2}$ ) can be found in the work of Fiederle et al., ${ }^{34}$ in the PICTS measurements on CdZnTe:Cl samples grown by the traveling heater method (THM). This level might also correspond to the level at $\sim 0.4 \mathrm{eV}$ of Lee et al. ${ }^{8}$

Closely spaced $T_{11}\left(0.490 \mathrm{eV}, 3.5 \times 10^{-18} \mathrm{~cm}^{2}\right)$ and $T_{12}$ $\left(0.505 \mathrm{eV}, 2.4 \times 10^{-17} \mathrm{~cm}^{2}\right)$ traps can also be considered to be members of the same band, positioned very closely to each other in the forbidden energy gap. Comparing their peak position to our results, their peak maxima are positioned between our peaks at 233 and $270 \mathrm{~K}$, which also is partly covered by peak $P 5$ observed in the PICTS signal of Zumbiehl et al. ${ }^{26}$ This $P 5$ level has an activation energy of about $0.6 \mathrm{eV}$. One of the closest levels to this group is level P6 $\left(0.54 \mathrm{eV}, 1 \times 10^{-10} \mathrm{~cm}^{2}\right)$ observed in the PICTS of CdZnTe:Cl by Fiederle et al. ${ }^{34}$

Trap $T_{13}\left(0.628 \mathrm{eV}, 2.8 \times 10^{-17} \mathrm{~cm}^{2}\right)$ is very close to many of the levels reported in the literature. Castaldini et $a{ }^{22}$ reported a whole band between 0.55 and $0.65 \mathrm{eV}$, which they claim has acceptor character and relate to a $\mathrm{Zn}$ vacancy. This especially corresponds to their level $C(0.57 \mathrm{eV}, 3$ $\left.\times 10^{-12} \mathrm{~cm}^{2}\right)$. The electron trap $G\left(E_{C^{-}} 0.64 \mathrm{eV}\right)$ observed in the PICTS spectra of Castaldini et al. ${ }^{23}$ is attributed to a $\mathrm{Cd}$ interstitial $\left(\mathrm{Cd}_{i}^{++}\right)$. Zerrai et $a .^{24}$ found a hole trap with $E_{a}$ $=0.65 \mathrm{eV}$ in their DLTS measurements, which they claim is related to vanadium doping. In our TSC spectra, level $T_{13}$ has a peak maximum at $291 \mathrm{~K}$, which corresponds well to the PICTS level $W$ found in the work of Cavallini et al. ${ }^{25}$

We will now discuss the deep donor level $E_{\mathrm{DD}}$ in our simulations that is positioned $0.99 \mathrm{eV}$ below $E_{C}$. This level is responsible for dark conductivity as explained in the work of
Look et al. ${ }^{19}$ for an analogous so called "EL2" level in SI GaAs. This level plays an important role in compensation processes, and it is responsible for the SI nature of $\mathrm{CdZnTe}$ samples. Many authors ${ }^{26,27,29}$ theoretically predicted the existence of this level (band) at $0.7-0.9 \mathrm{eV}$ below $E_{C}$. There are many levels that fall within this (or a moderately larger) energy range and that have been presented in the literature, for example, the PICTS level P7 $(0.9 \mathrm{eV})$ of Zumbiehl et $a{ }^{26}$ and the CL-PICTS levels $D(0.77-0.78 \mathrm{eV})$ and $E$ (1.05-1.1 eV) of Castaldini et al. ${ }^{22}$ Level $H_{1}$ (0.79) from work of Castaldini et $a l^{23}$ as well as levels $C(0.96 \mathrm{eV})$ and $D(1.09 \mathrm{eV})$ obtained by Drighil et al. ${ }^{27}$ also belong in this category. Electron trap $E_{3}(0.85 \mathrm{eV})$ from the PICTS measurements of Zerrai et al. ${ }^{7}$ should be mentioned as well.

\section{CONCLUSIONS}

Deep trap levels in SI CdZnTe ternary detector material were characterized by the SIMPA method fitted to the results of TSC measurements. TSC spectra were used in which electron-hole pairs were created by the use of $5 \mathrm{MeV}$ focused proton beam irradiation. Charge carriers were captured in the deep traps and afterward released by the thermal emission, which was recorded in the 90-300 K range. It was shown that the obtained TSC spectra could be well fitted with the unique set of 14 different deep traps, which were all completely and simultaneously characterized. The obtained trap data are in good accordance with earlier deep trap characterization results found in the literature, achieved through many different methods on similar materials. Our results also confirm that the use of a proton beam for the creation of charge carriers results in valuable TSC measurements and consequently to reliable and complete deep trap characterization and cataloguing.

${ }^{1}$ Z.-Q. Fang and D. C. Look, J. Appl. Phys. 69, 8177 (1991).

${ }^{2}$ U. V. Desnica and B. Šantić, J. Appl. Phys. 67, 1408 (1990).

${ }^{3}$ M. Pavlović and U. V. Desnica, Jpn. J. Appl. Phys., Part 1 37, 4687 (1998).

${ }^{4}$ B. Šantić and U. V. Desnica, Appl. Phys. Lett. 56, 2636 (1990).

${ }^{5}$ Z. C. Huang, K. Xie, and C. R. Wie, Rev. Sci. Instrum. 62, 1951 (1991).

${ }^{6}$ K. Xie, Z. C. Huang, and C. R. Wie, J. Electron. Mater. 20, 553 (1991).

${ }^{7}$ A. Zerrai, K. Cherkaoui, G. Marrakchi, G. Bremond, P. Fougeres, M. Hage-Ali, J. M. Koebel, and P. Siffert, J. Cryst. Growth 197, 646 (1999).

${ }^{8}$ E. Y. Lee, R. B. James, R. W. Olsen, and H. Hermon, J. Electron. Mater. 28, 766 (1999).

${ }^{9}$ P. Fougeres, M. Hage-Ali, J. M. Koebel, P. Siffert, S. Hassan, A. Lusson, R. Triboulet, G. Marrakchi, A. Zerrai, K. Cherkaoui, R. Adhiri, G. Bremond, O. Kaitasov, M. O. Ruault, and J. Crestou, J. Cryst. Growth 184-185, 1313 (1998).

${ }^{10}$ E. Vittone, F. Fizzotti, A. LoGiudice, C. Paolini, and C. Manfredfotti, Nucl. Instrum. Methods Phys. Res. B 161-163, 446 (2000).

${ }^{11}$ C. Manfredotti, F. Fizzotti, A. LoGiudice, M. Jakšić, Ž. Pastuović, C. Paolini, P. Olivero, and E. Vittone, Mater. Sci. Eng., B 102, 193 (2003).

${ }^{12}$ Z. Medunić, M. Jakšić, Ž. Pastuović, and N. Skukan, Nucl. Instrum. Methods Phys. Res. B 210, 237 (2003).

${ }^{13}$ Z. Medunić, M. Jakšić, Ž. Pastuović, and N. Skukan, Nucl. Instrum. Methods Phys. Res. B 231, 486 (2005).

${ }^{14}$ M. Pavlović and U. V. Desnica, J. Appl. Phys. 84, 2018 (1998).

${ }^{15}$ M. Pavlović, U. V. Desnica, and J. Gladić, J. Appl. Phys. 88, 4563 (2000).

${ }^{16}$ J. P. Biersack and L. G. Haggmark, Nucl. Instrum. Methods 174, 257 (1980).

${ }^{17}$ U. V. Desnica, M. Pavlović, Z.-Q. Fang, and D. C. Look, J. Appl. Phys. 92, 4126 (2002).

${ }^{18}$ M. Pavlović, U. V. Desnica, Z.-Q. Fang, and D. C. Look, Vacuum 71, 153 (2003). 
${ }^{19}$ D. C. Look and Z.-Q. Fang, Solid-State Electron. 43, 1317 (1999).

${ }^{20}$ B. Šantić, N. Radić, and U. V. Desnica, Solid State Commun. 79, 535 (1991).

${ }^{21}$ K. Suzuki, S. Seto, A. Iwata, M. Bingo, T. Sawada, and K. Imai, J. Electron. Mater. 29, 704 (2000), and references therein.

${ }^{22}$ A. Castaldini, A. Cavallini, B. Fraboni, P. Fernandez, and L. Polenta, Phys. Rev. B 54, 7622 (1996), and references therein.

${ }^{23}$ A. Castaldini, A. Cavallini, B. Fraboni, P. Fernandez, and J. Piqueras, J. Appl. Phys. 83, 2121 (1998).

${ }^{24}$ A. Zerrai, M. Dammak, G. Marrakchi, G. Bremond, R. Triboulet, and Y. Marfaing, J. Cryst. Growth 197, 729 (1999).

${ }^{25}$ A. Cavallini, B. Fraboni, W. Dusi, A. Auricchio, M. Zanarini, and P. Chirco, Appl. Phys. A: Mater. Sci. Process. 75, 427 (2002)

${ }^{26}$ A. Zumbiehl, P. Fougeres, M. Hage-Ali, J. M. Koebel, P. Siffert, A. Zerrai, K. Cherkaoui, G. Marrakchi, and G. Bremond, J. Cryst. Growth 197, 670 (1999), and references therein.
${ }^{27}$ A. Drighil, R. Adhiri, C. Sribi, M. Mousstad, K. Cherkaoui, G. Marrakchi, A. Zerrai, and M. Zazoui, Moroccan Journal of Condensed Matter 2, 54 (1997); http://www.fsr.ac.ma/MJCM/vol2-art10.pdf

${ }^{28}$ G. Martel, A. Hideur, C. Lefebvre, C. Özkul, M. Hage-Ali, and J. M. Koebbel, Appl. Phys. B: Lasers Opt. 70, 77 (2000).

${ }^{29}$ C. Szeles, IEEE Trans. Nucl. Sci. 51, 1242 (2004).

${ }^{30}$ M. Fiederle, T. Feltgen, J. Meinhardt, M. Rogalla, and K. W. Benz, J. Cryst. Growth 197, 635 (1999).

${ }^{31}$ S. A. Awadalla, A. W. Hunt, K. W. Lynn, H. Glass, C. Szeles, and S.-H. Wei, Phys. Rev. B 69, 075210 (2004).

${ }^{32}$ K. Suzuki, K. Inagaki, N. Kimura, I. Tsubono, T. Sawada, K. Imai, and S. Seto, Phys. Status Solidi A 147, 203 (1995).

${ }^{33}$ T. L. Larsen, C. F. Varotto, and D. A. Stevenson, J. Appl. Phys. 43, 172 (1972).

${ }^{34}$ M. Fiederle, V. Babentsov, J. Franc, A. Fauler, and J.-P. Konrath, Cryst. Res. Technol. 38, 588 (2003). 